\title{
Volume of Distribution is Unaffected by Metabolic Drug-Drug Interactions
}

\author{
Jasleen K. Sodhi ${ }^{1}$ - Caroline H. Huang ${ }^{1} \cdot$ Leslie Z. Benet ${ }^{1}[$
}

Published online: 28 July 2020

(c) Springer Nature Switzerland AG 2020

\begin{abstract}
Introduction It has been recognized that significant transporter interactions result in volume of distribution changes in addition to potential changes in clearance. For drugs that are not clinically significant transporter substrates, it is expected that drug-drug interactions would not result in any changes in volume of distribution.

Methods An evaluation of this hypothesis proceeded via an extensive analysis of published intravenous metabolic drug-drug interactions, based on clinically recommended index substrates and inhibitors of major cytochrome P450 (CYP) isoforms. Results Seventy-two metabolic drug interaction studies were identified where volume of distribution at steady-state $\left(V_{\mathrm{ss}}\right)$ values were available for the CYP index substrates caffeine (CYP1A2), metoprolol (CYP2D6), midazolam (CYP3A4), theophylline (CYP1A2), and tolbutamide (CYP2C9). Changes in exposure (area under the curve) up to 5.1-fold were observed; however, ratios of $V_{\mathrm{ss}}$ changes have a range of $0.70-1.26$, with one outlier displaying a $V_{\mathrm{ss}}$ ratio of 0.57 .

Discussion These results support the widely held founding tenant of pharmacokinetics that clearance and $V_{\mathrm{ss}}$ are independent parameters. Knowledge that $V_{\mathrm{ss}}$ is unchanged in metabolic drug-drug interactions can be helpful in discriminating changes in clearance from changes in bioavailability $(F)$ when only oral dosing data are available, as we have recently demonstrated. As $V_{\mathrm{ss}}$ remains unchanged for intravenous metabolic drug-drug interactions, following oral dosing changes in $V_{\mathrm{ss}} / F$ will reflect changes in $F$ alone. This estimation of $F$ change can subsequently be utilized to assess changes in clearance alone from calculations of apparent clearance. Utilization of this simple methodology for orally dosed drugs will have a significant impact on how drug-drug interactions are interpreted from drug development and regulatory perspectives.
\end{abstract}

\section{Introduction}

Volume of distribution in pharmacokinetics is the theoretical volume in which a drug must distribute to relate the observed systemic drug concentrations to the amount of drug present in the body. It is a non-physiologic volume that reflects the degree of tissue distribution of a drug. It has been recognized that xenobiotic transporters can influence volume of distribution of drugs by allowing or restricting drug access to various tissues throughout the body [1], and therefore significant transporter drug interactions may result in changes in volume of distribution in addition to potential changes in clearance (CL) [2]. For drugs that are not clinically significant

Leslie Z. Benet

leslie.benet@ucsf.edu

1 Department of Bioengineering and Therapeutic Sciences, Schools of Pharmacy and Medicine, University of California San Francisco, 513 Parnassus Ave, Rm HSE 1164, UCSF, Box 0912, San Francisco, CA 94143, USA transporter substrates, it is expected that drug-drug interactions (DDIs) would not result in any changes in the steadystate volume of distribution $\left(V_{\mathrm{ss}}\right)$. As our laboratory has recently demonstrated, knowledge that $V_{\mathrm{ss}}$ is unchanged in metabolic DDIs can be helpful in implicating transporter involvement in complex DDIs as well as in facilitating the discrimination of changes in CL from changes in bioavailability $(F)$ when only oral dosing data are available [3]. Here, we present a comprehensive evaluation of the hypothesis that $V_{\mathrm{ss}}$ remains unchanged in metabolic drug interaction studies.

\section{Methods}

\subsection{Literature Search Strategy and Inclusion/ Exclusion Criteria}

Based on a recent compilation of recommended clinical index substrates of major drug-metabolizing enzymes and cytochrome P450 (CYP) isoforms [4], a comprehensive 


\section{Key Points}

While it is expected that significant xenobiotic transporter interactions will result in volume of distribution changes of a victim drug, metabolic drug interactions should not result in any volume of distribution changes.

Evaluation of exemplary metabolic drug-drug interactions with clinically recommended index substrates and inhibitors indicates that volume of distribution is largely unchanged in metabolic interactions, highlighting that volume and clearance are indeed independent parameters.

Understanding that metabolic interactions do not result in volume changes can allow for estimation of bioavailability changes in oral drug-drug interactions. Examination of the extent of change in the apparent volume of distribution will reflect changes in bioavailability alone due to the unchanged volume of distribution.

Estimates of changes in bioavailability can subsequently be utilized to differentiate changes in clearance alone from measures of apparent clearance following oral dosing, as we have recently demonstrated [3].

literature search identified caffeine (CYP1A2), metoprolol (CYP2D6), midazolam (CYP3A4), theophylline (CYP1A2), and tolbutamide (CYP2C9) as index substrates for which intravenous (IV) dosing drug interaction data were available. Oral drug interaction studies of these index substrates were excluded from the analysis to avoid the confounding impact that changes in $F$ would have on apparent volume of distribution $\left(V_{\mathrm{ss}} / F\right)$. Owing to the large number of IV interaction studies for the probe substrate midazolam, the scope of the analysis was further refined to primarily include DDIs involving index inhibitors with known clinical inhibitory specificities against the various CYP isoforms and xenobiotic transporters, again based on the recent recommendations of Tornio et al. [4]. If additional victim-perpetrator combinations were investigated in these studies, these interaction data were also included in the analysis and information regarding the in-vivo substrate or inhibitory specificities of these drugs was referenced from the literature [5-11]. As $V_{\mathrm{ss}}$ is not often reported by clinical investigators, estimation of this parameter often proceeded via digitization and noncompartmental analysis of published PK profiles. If $V_{\mathrm{ss}}$ was not reported, studies were excluded if (1) PK profiles were not reported and/or were difficult to reliably digitize or if (2) resulting estimates of area under the curve (AUC) were greater than $25 \%$ different from reported values. The latter aspect is further discussed in the next section.
This analysis focuses on DDI studies conducted with the same subjects in the control and treatment arms, and as such, four midazolam studies with a parallel study design were excluded. However, some studies included in this analysis conducted the DDI investigation (within the same person) in multiple populations, for example, with respect to pharmacogenomic variance of drug-metabolizing enzymes or in healthy vs disease-state subjects. Thus, we also analyze changes in $V_{\mathrm{ss}}$ of the victim drug only between these populations to investigate the inherent potential of $V_{\mathrm{ss}}$ to change between different individuals.

The specificities of all substrates and inhibitors are summarized, and in addition, the Biopharmaceutics Drug Disposition Classification System is listed. This simple system classifies drugs based on solubility and permeability and can anticipate when metabolism vs transporter-mediated processes (such as renal and biliary elimination) are the major route of drug elimination [12].

\subsection{Data Analyses}

Thirty published DDI studies were examined and changes in exposure (AUC), CL, $V_{\text {ss }}$, mean residence time (MRT), and terminal half-life $\left(t_{1 / 2, z}\right)$ were calculated and reported as ratios of interaction/control. When individual PK data were reported, the ratios of the parameters of interest were calculated for each individual and the average of this ratio for all subjects was reported (and indicated in the tables with a footnote). Although the initial volume of distribution in the central compartment and the terminal volume of distribution $\left(V_{z}\right)$ are commonly reported in clinical PK studies, our primary analysis was based on changes in $V_{\mathrm{ss}}$ as it is a non-compartmental parameter that represents the wholebody volume of distribution, theoretically is independent of elimination measures [13], and is not associated with a particular compartment or phase of the PK curve (as is the case for volume of distribution in the central compartment and $V_{z}$ for drugs that display multi-compartment kinetics). Methods of each paper were carefully reviewed to ensure reported $V_{\mathrm{ss}}$ was appropriately calculated. For investigations in which $V_{\text {ss }}$ could not be determined, data for $V_{z}$ were reported with the understanding that $V_{z}$ changes will only reflect the same degree of change as $V_{\mathrm{ss}}$ if the victim drug follows a onecompartment model or if the distribution phase minimally affects measures of both AUC and area under the moment curve (AUMC).

For investigations that did not explicitly report all parameters of interest, the parameter was either (1) back calculated from reported data or (2) estimated by digitization of reported plasma concentration-time profiles. Clearance and AUC could be calculated from one another if only one of the two parameters were reported by using a known dose and the equation: $\mathrm{CL}=$ dose/AUC. Similarly, $\mathrm{CL}$ can be used to 
calculate either $V_{\mathrm{ss}}$ or MRT (if one of the two parameters were reported) using Eq. (1) [13]:

$V_{\mathrm{ss}}=\mathrm{CL} \cdot \mathrm{MRT}$.

If MRT values were not reported, MRT was calculated via non-compartmental methods by Eq. (2):

MRT $=\frac{\text { AUMC }}{\text { AUC }}-$ MIT,

where MIT is the mean input time. For IV bolus doses, MIT is zero. For IV infusions, MIT is defined as half of the length of the dosing interval $(\tau)$, i.e., MIT $=\tau / 2$. For investigations that did not report $V_{\mathrm{ss}}$ (or any of the other PK parameters of interest), plasma concentration-time profiles were digitized using WebPlotDigitizer Version 4.2 (Ankit Rohatgi, San Francisco, CA, USA) and analyzed by a non-compartmental analysis with WinNonlin Professional Edition Version 2.1 (Pharsight, Mountain View, CA, USA). Digitized AUC values were compared to reported AUC values and studies were excluded if reported average AUC values were greater than $25 \%$ different from digitized values. All PK ratios calculated from digitization of published concentration-time profiles are specifically indicated in the data tables with a footnote. Published values of PK parameters were reported in priority, with digitization/reanalysis of reported average concentration-time profiles utilized only to supplement unreported data. Each value in the data tables is annotated based on calculation methods (published vs digitized, individual vs average PK data used for ratios, equations used, or assumptions made).

The average absolute differences in AUC and $V_{\mathrm{ss}}$ were compared to one another for all 72 DDIs, as well as the subset of DDIs with a greater than $30 \%$ AUC change (i.e., ratios outside of the range of 0.77 and $1.30, n=49$ ), which could be considered a potentially clinically significant interaction. To account for interactions resulting in a decrease in AUC, such as potential enzyme induction, the inverse for all ratios less than unity was utilized in calculation of average absolute AUC and $V_{\mathrm{ss}}$ changes. Box plot representations of the data were generated to allow visual depiction of any differences in the degree of change in these two parameters, which indicate the median and 25th and 75th percentiles, range from minimum to maximum values, and depict each individual point. To investigate if the classic trend of CL changes being equal (but opposite in magnitude) to half-life and MRT changes in these metabolic DDIs, the relationship between changes in half-life and MRT were compared to the inverse of the change in CL.

\section{Results}

Relevant information on the specificity of all substrates analyzed are outlined in Table 1 and the inhibitory specificities of the perpetrator drugs included in this analysis are listed in Table 2. The comprehensive literature search identified DDI studies for the following index substrates where $V_{\mathrm{ss}}$ measurements were available: caffeine [14], metoprolol [15], midazolam [16-25], theophylline [26-38], and tolbutamide [39] (Table 3). Any additional victim-perpetrator combinations (with non-index substrates) investigated in these studies where $V_{\mathrm{ss}}$ measurements were available were also analyzed, including alfentanil [20], antipyrine [27], and lidocaine [19] (Table 4). When only $V_{z}$ values were available, these studies are summarized in Table 5 and include the victim drugs antipyrine [40], desipramine [41], imipramine [41], and theophylline [40, 42-44].

The changes in PK parameters (AUC, CL, $V_{\mathrm{ss}}$, MRT, and $t_{1 / 2, z}$ ) of clinically recommended index substrates are listed in Table 3 and additional victim drugs in Table 4, totaling 72 DDI studies. For these primarily metabolized drugs, the AUC ratio range was $0.44-5.1$ while the $V_{\mathrm{ss}}$ range was 0.57-1.40. The average absolute difference in AUC ratios for these 72 DDI studies averaged $1.69 \pm 0.78$, while the average absolute difference in $V_{\mathrm{ss}}$ averaged $1.10 \pm 0.12$. For the 49 interactions with at least a $30 \%$ change, i.e., those interactions that could potentially be clinically significant, the absolute AUC changes averaged $1.95 \pm 0.83$, while $V_{\mathrm{ss}}$ averaged $1.11 \pm 0.13$. Figure 1 depicts box plot representations of these values. Of the 72 DDI studies examined, only three $(4.2 \%)$ resulted in a greater than $30 \%$ change in $V_{\text {ss }}$ (i.e., ratios outside of the range of $0.77-1.30$ ) with ratios of 0.70 [15], 1.40 [18], and 0.57 [24].

An additional ten DDI studies were identified from five studies for which only $V_{z}$ was reported and $V_{\text {ss }}$ could not be determined (due to a lack of published PK profiles) (Table 5). Changes in AUC had a range of 1.10-1.70, but $V_{z}$ had only a range of $0.89-1.24$.

While the inclusion criteria of this analysis focused on studies that include the same patients in the control and interaction phases, three DDI studies investigated here performed the same drug interaction study in multiple groups, either with respect to pharmacogenomic variance of the metabolizing enzyme $[15,21]$ or disease state [28]. To investigate the impact of inter-individual variability on $V_{\mathrm{ss}}$, the control phase (victim drug only) between each group were compared to one another (Table 6). When comparing the pharmacokinetics of the index substrate alone between groups, $V_{\mathrm{ss}}$ for the victim drug was observed to change with ratios of 0.51 (metoprolol with CYP2D6 pharmacogenomics), 0.72 and 
Table 1 Enzyme specificities of clinical index substrates and additional victim drugs

\begin{tabular}{lllll}
\hline Substrate & BDDCS class & Enzyme & Other relevant enzymes/transporters & Refs. \\
\hline Antipyrine & 1 & CYP1A2 & Multiple CYPs (2A6, 2B6, 2C, 2E1) & {$[7]$} \\
CYP2C9 & & \\
Alfentanil & 1 & CYP3A & & \\
Caffeine & 1 & CYP3A & - & {$[5]$} \\
Desipramine & 1 & CYP2D6 & CYP3A & {$[4]$} \\
Imipramine & 1 & CYP2C19 & CYP2D6 & {$[4]$} \\
Lidocaine & 1 & CYP3A & CYP1A2 & {$[5]$} \\
Metoprolol & 1 & CYP2D6 & CYP3A & {$[7]$} \\
Midazolam & 1 & CYP3A & - & {$[4]$} \\
Theophylline & 1 & CYP1A2 & CYP2E1 & {$[4]$} \\
Tolbutamide & 2 & CYP2C9 & OAT2 & {$[4]$} \\
\hline
\end{tabular}

BDDCS Biopharmaceutics Drug Disposition Classification System, CYP cytochrome P450, OAT organic anion transporter, Refs references
0.79 (midazolam with CYP3A5 pharmacogenomics), and 0.70 (healthy patients vs patients with liver cirrhosis), while AUC was observed to change 0.98 - to 2.56-fold in these studies. In the same studies, however, minimal change in $V_{\mathrm{ss}}$ was observed in the same individual between the drug interaction and control phases, with a ratio range of $0.70-1.13$ (Table 3).

\section{Discussion}

For primarily metabolized drugs, IV drug interaction studies resulted in minimal changes to $V_{\text {ss }}$. Changes in drug exposure (AUC) up to 5.1-fold were observed; however, ratios of $V_{\text {ss }}$ changes only had a range of $0.70-1.40$, with one outlier displaying a $43 \%$ decrease in $V_{\text {ss }}$ (ratio of 0.57 ) (Table 3 ) for a midazolam-ketoconazole interaction in healthy female Koreans where the AUC ratio was 4.61 [24]. In contrast, a second midazolam-ketoconazole interaction study in healthy white subjects with a similar AUC ratio of 5.1 only exhibited a $V_{\text {ss }}$ ratio of 1.20 [23]. The trend of unchanged $V_{\text {ss }}$ was observed for all index substrates and CYP isoforms investigated (caffeine and theophylline, CYP1A2; metoprolol, CYP2D6; tolbutamide, CYP2C9; midazolam, CYP3A4) [data not shown].

It should be noted that a listed high percent AUC extrapolation value does not necessarily indicate that AUCs (or PK parameters derived from AUCs) are unreliable if the slope of the elimination phase is adequately captured. Additionally, the PK parameters reported by the original authors were used in priority to calculate the ratios presented in this analysis, such as the frequently reported parameters AUC, $\mathrm{CL}$, and $t_{1 / 2, z}$. Estimation of less frequently reported parameters, such as $V_{\mathrm{ss}}$ and MRT, proceeded via digitization of the average concentration-time profiles reported by the original authors, and it should be noted that these average profiles may not accurately represent changes within any one particular individual in the DDI study.

When $V_{\text {ss }}$ was not reported (and could not be calculated because of the lack of published PK curves), changes in $V_{z}$ were examined (Table 5). Changes in $V_{z}$ were minimal (0.89-1.24). Examination of theophylline PK curves from the other studies in this analysis indicate that the distribution phase of theophylline is very short, and therefore $V_{z}$ changes would likely be similar to $V_{\mathrm{ss}}$ changes. No such conclusions related to the potential similarity between $V_{z}$ and $V_{\text {ss }}$ could be made for the antipyrine, desipramine, or imipramine data because of the lack of published IV PK curves in the other studies examined here.

Of note, the clinical studies included in this analysis were all conducted with the same individuals in the control vs interaction arms, to minimize the confounding effects of inter-individual variability. Three of the studies examined here also conducted DDIs in multiple subject groups with respect to disease-state [28] or pharmacogenomic variance of drug-metabolizing enzymes $[15,21]$. To examine the potential impact of inter-individual differences in $V_{\text {ss }}$, the PK parameters associated with the control arms (victim drug only) of each group were compared to one another, resulting in $V_{\text {ss }}$ ratios of $0.51-0.79$ associated with AUC changes of 0.98-2.56 (Table 6). In comparison to the earlier part of this analysis where changes in $V_{\text {ss }}$ within the same individual (with and without addition of a perpetrator drug) were examined, these same studies displayed $V_{\text {ss }}$ ratios of 0.70-1.26 associated with AUC increases of 1.12-3.08. Reported data related to the body weights of individuals in each arm are also noted in Table 5. However, accounting for average differences in body weight between the two groups 
Table 2 Inhibitory specificities of clinical index inhibitors and additional perpetrator drugs

\begin{tabular}{|c|c|c|c|c|}
\hline Index inhibitor & BDDCS class & Enzyme & $\begin{array}{l}\text { Other relevant enzymes/ } \\
\text { transporters }\end{array}$ & Refs. \\
\hline Cimetidine & 3 & $\begin{array}{l}\text { ОСТ2 } \\
\text { CYP2C19 } \\
\text { CYP3A }\end{array}$ & $\begin{array}{l}\text { MATE1 } \\
\text { CYP1A2 } \\
\text { CYP2C9 } \\
\text { CYP2D6 }\end{array}$ & {$[5]$} \\
\hline Ciprofloxacin & 4 & CYP1A2 & CYP3A4 & {$[4]$} \\
\hline Clarithromycin & 3 & CYP3A4 & $\begin{array}{l}\text { CYP2C19 } \\
\text { P-gp }\end{array}$ & [4] \\
\hline Diltiazem & 1 & CYP3A4 & $\begin{array}{l}\text { CYP1A2 } \\
\text { CYP2D6 } \\
\text { P-gp }\end{array}$ & {$[5]$} \\
\hline Disulfiram & 2 & CYP2E1 & $\begin{array}{l}\text { CYP1A2 } \\
\text { CYP2C9 } \\
\text { CYP2D6 }\end{array}$ & {$[5]$} \\
\hline Enoxacin & 4 & CYP1A2 & & [4] \\
\hline Erythromycin & 4 & CYP3A4 & P-gp & {$[4]$} \\
\hline Famotidine & 3 & Unknown & & \\
\hline Fluconazole & 3 & $\begin{array}{l}\text { CYP2C9 } \\
\text { CYP2C19 }\end{array}$ & CYP3A4 & [4] \\
\hline Itraconazole & 2 & CYP3A4 & $\begin{array}{l}\text { CYP2J2 } \\
\text { P-gp }\end{array}$ & [4] \\
\hline Ketoconazole & 2 & CYP3A4 & $\begin{array}{l}\text { CYP2C19 } \\
\text { P-gp }\end{array}$ & [4] \\
\hline Lidocaine & 1 & CYP3A4 & CYP1A2 & [7] \\
\hline Nalidixic acid & 2 & Unknown & & \\
\hline Nelfinavir & 2 & CYP3A4 & CYP2D6 & [8] \\
\hline Norfloxacin & 4 & CYP1A2 & & [9] \\
\hline Ofloxacin & 3 & Unknown & & \\
\hline Olanzapine & 2 & Unknown & & \\
\hline Ondansetron & 1 & Unknown & & \\
\hline Primaquine & 1 & Unknown & & \\
\hline Quinidine & 1 & CYP2D6 & P-gp & [4] \\
\hline Ranitidine & 3 & $\begin{array}{l}\text { OCT2 } \\
\text { CYP3A }\end{array}$ & $\begin{array}{l}\text { CYP2C9 } \\
\text { CYP2D6 }\end{array}$ & [5] \\
\hline Rifampin (single dose) & 2 & OATPs & CYP3A4 & {$[6,11]$} \\
\hline Rifampin (multiple dose) & 2 & $\begin{array}{l}\text { (Inducer) } \\
\text { CYP3A } \\
\text { CYP2C9 } \\
\text { P-gp }\end{array}$ & $\begin{array}{l}\text { (Inducer) } \\
\text { CYP1A } \\
\text { CYP2B6 } \\
\text { CYP2C8 } \\
\text { CYP2C19 }\end{array}$ & [6] \\
\hline Ritonavir (single dose) & 2 & CYP3A4 & P-gp & {$[4]$} \\
\hline Ritonavir (multiple dose) & 2 & CYP induction & & [4] \\
\hline Sulfaphenazole & 1 & CYP2C9 & & {$[8]$} \\
\hline Terbinafine & 2 & CYP2D6 & CYP1A2 & {$[4]$} \\
\hline Verapamil & 1 & CYP3A4 & P-gp & [4] \\
\hline
\end{tabular}

BDDCS Biopharmaceutics Drug Disposition Classification System, CYP cytochrome P450, MATE Multidrug and Toxic Extrusion, $O C T$ organic cation transporter, $P$-gp P-glycoprotein, Refs references does not necessarily result in $V_{\text {ss }}$ ratios that are closer to unity. For instance, the reported differences in metoprolol $V_{\mathrm{ss}}$ between CYP2D6 poor metabolizers and extensive metabolizers resulted in a ratio of 0.51 , and the reported values used to calculate this ratio were normalized by body weight of each individual by the original investigators. This indicates that volume of distribution differences in different individuals can be significant and do not only depend on total body weight differences. Further, the variability associated with $V_{\text {ss }}$ values was much greater in extensive metabolizers than poor metabolizers, with $\mathrm{CV}$ values of $44 \%$ and $22 \%$, respectively. The issue of variability between individuals is further 


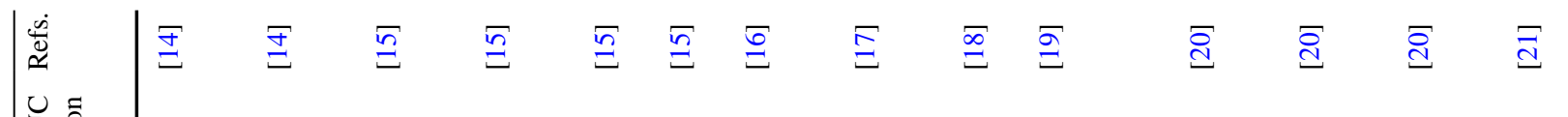

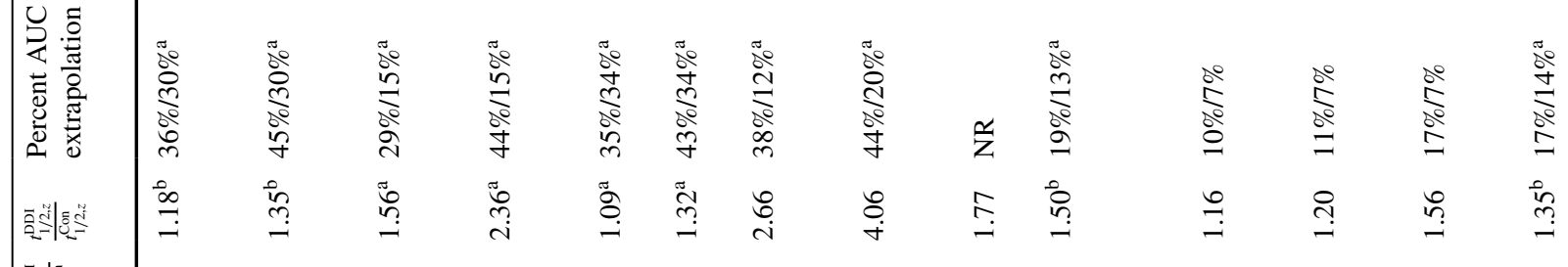

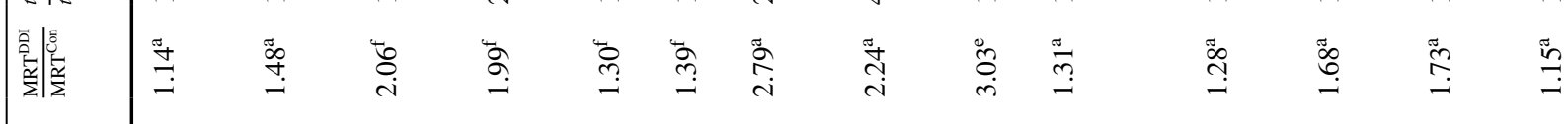

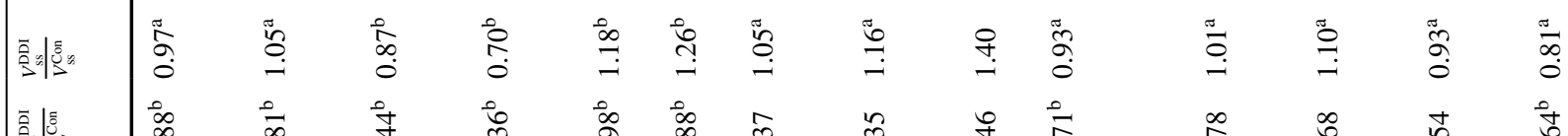

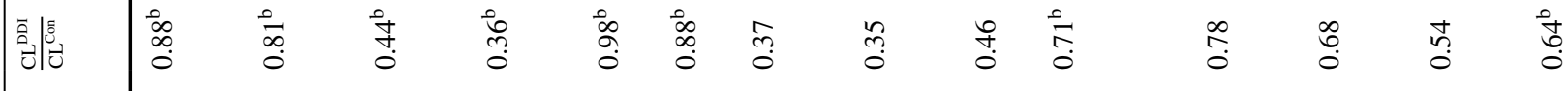

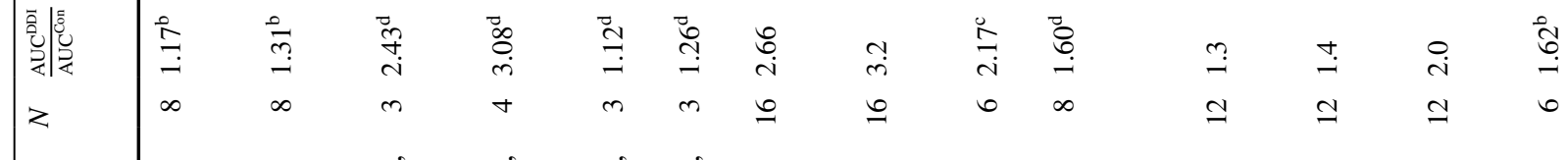

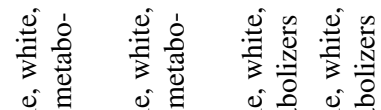

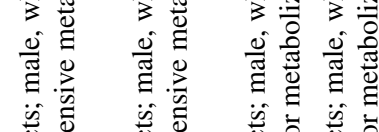

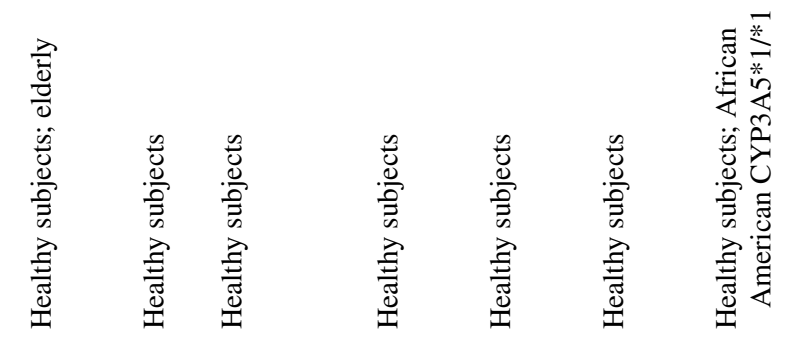

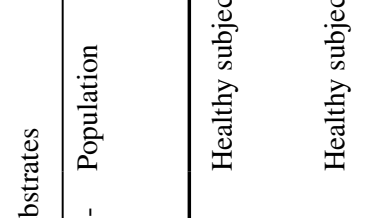

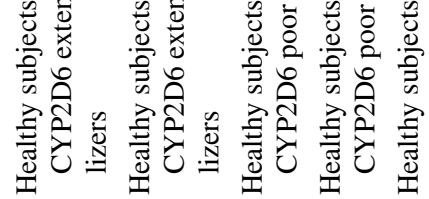

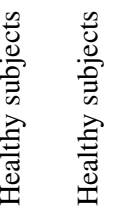

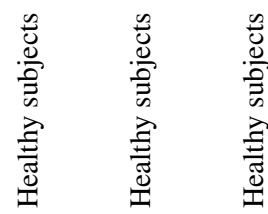

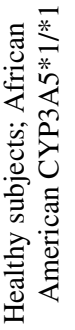

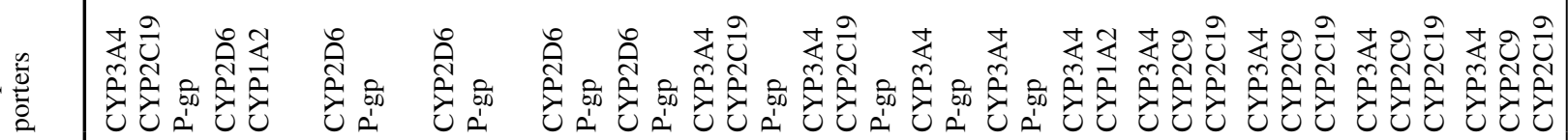

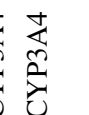

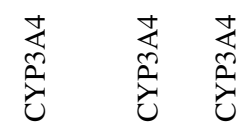

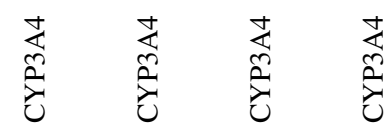

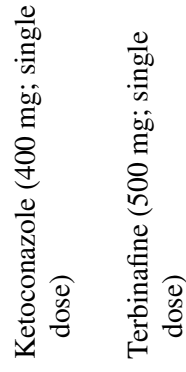

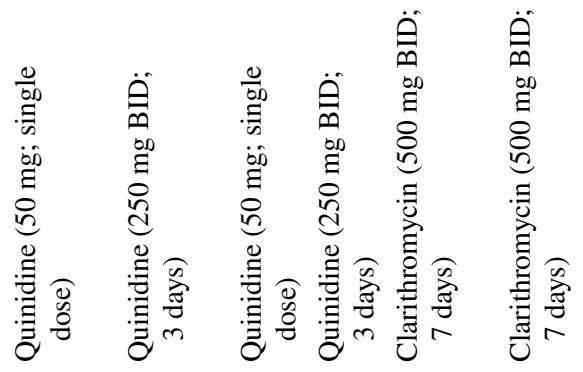

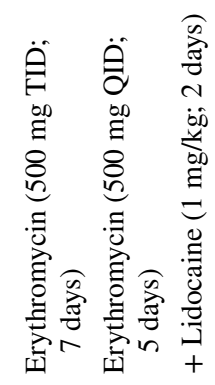

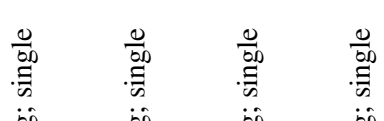

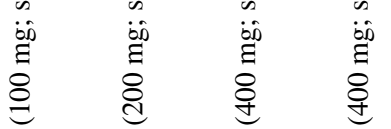

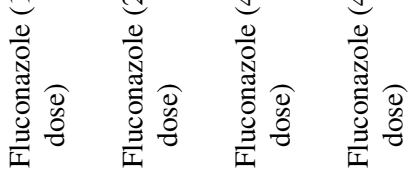

क्ञ

ह્ટ

辛 


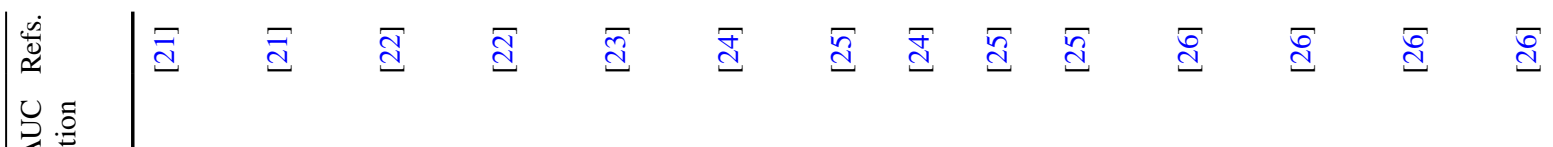

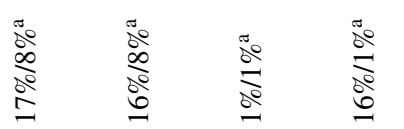

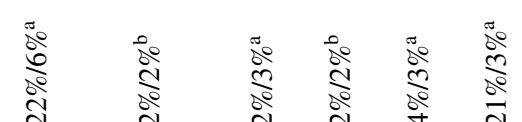
首兑 兑 兑

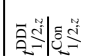

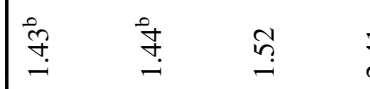
商部

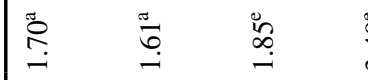

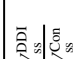
مू

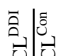
茴 ñ
氛惫
$z$

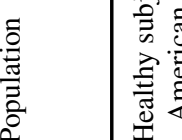

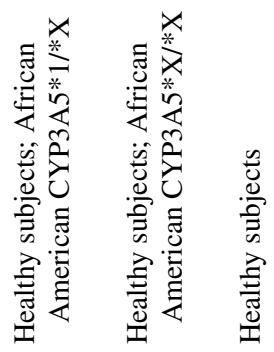

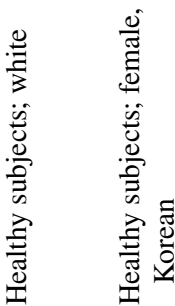

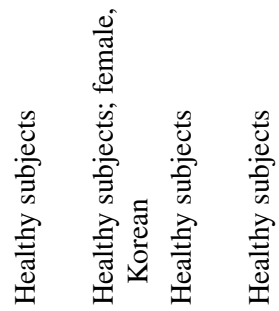

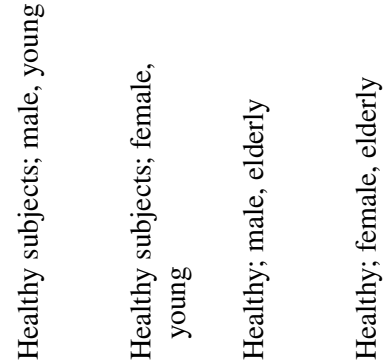

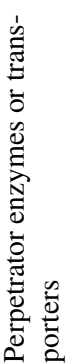

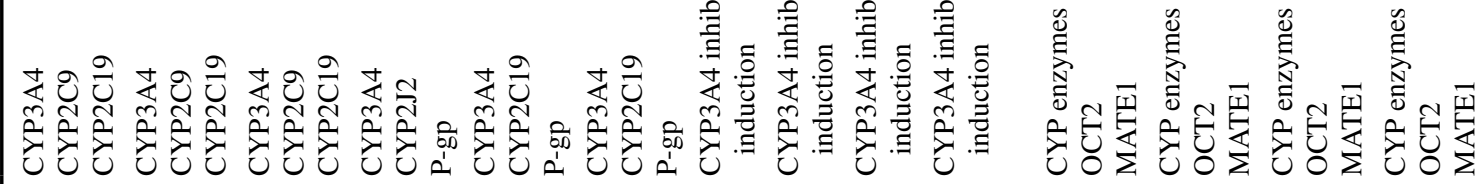

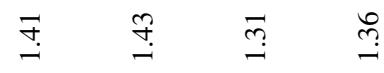

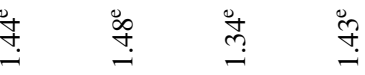

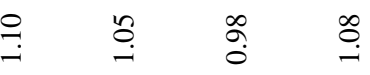

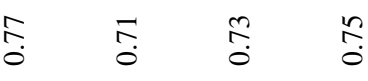

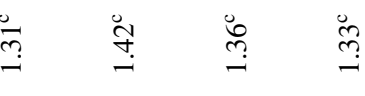




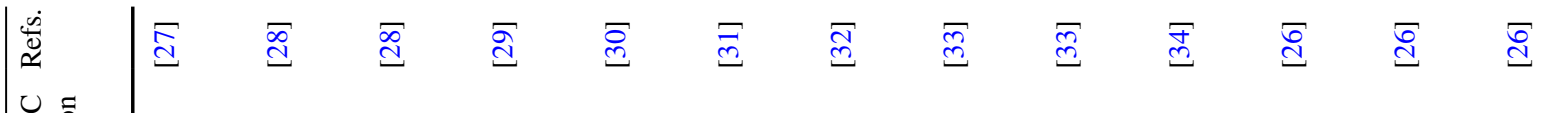

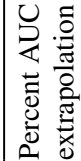

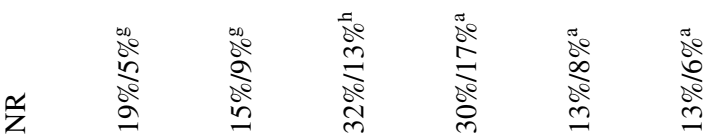

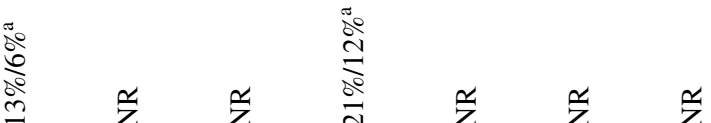

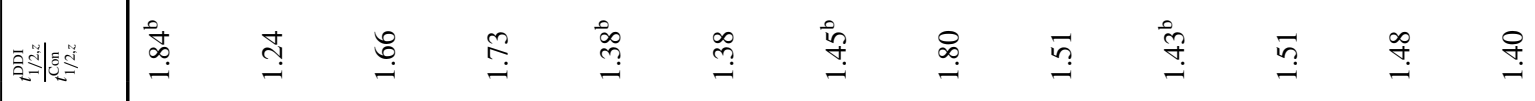

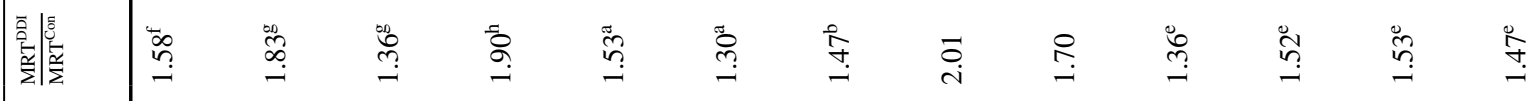

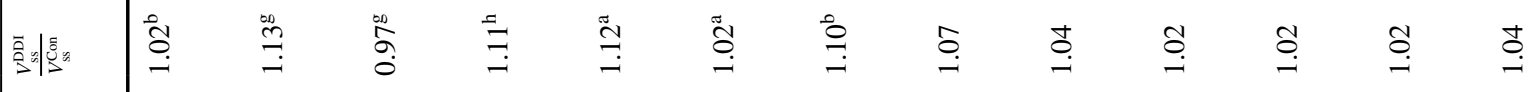

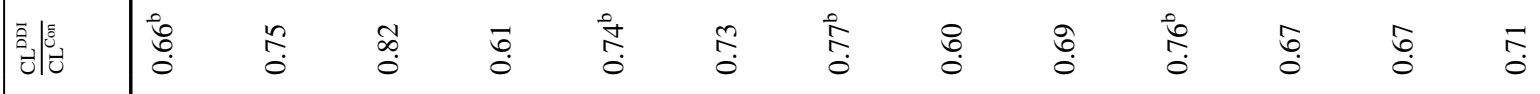

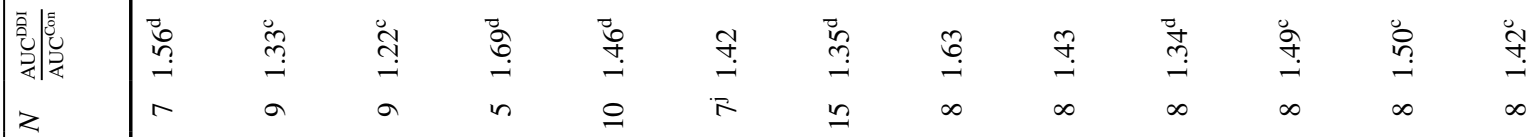

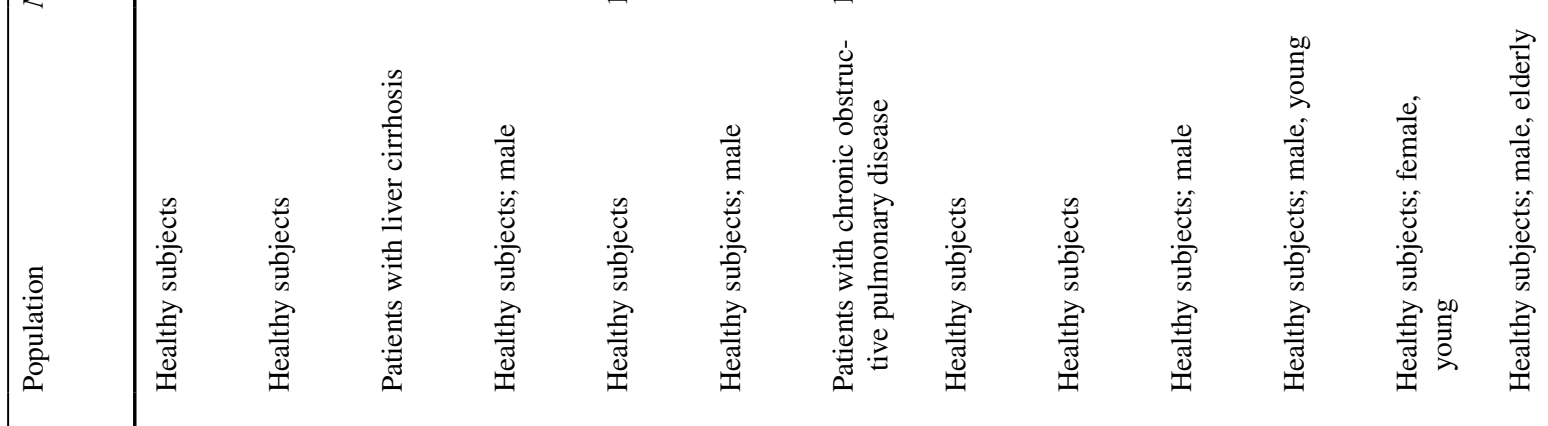
㝘

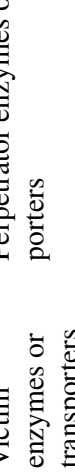

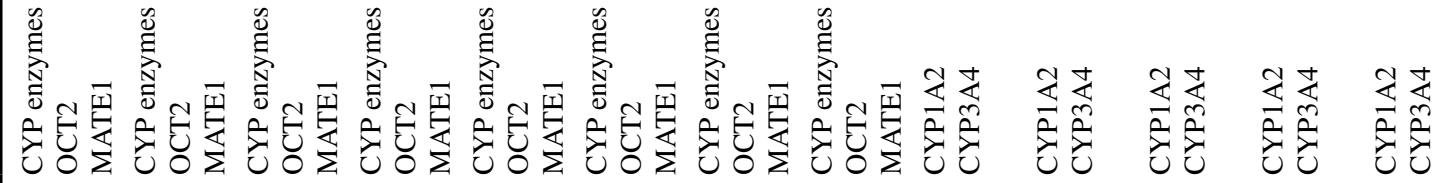

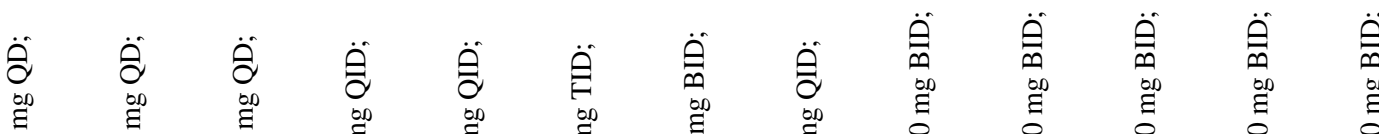

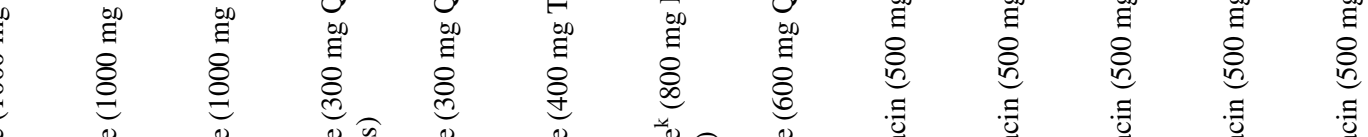

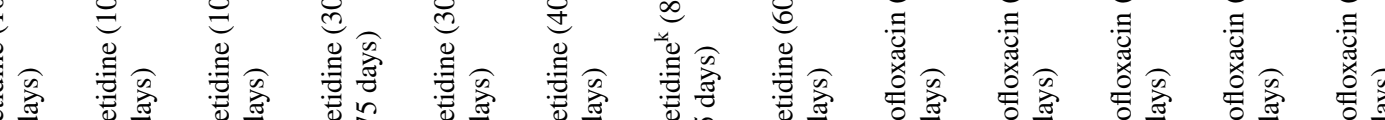

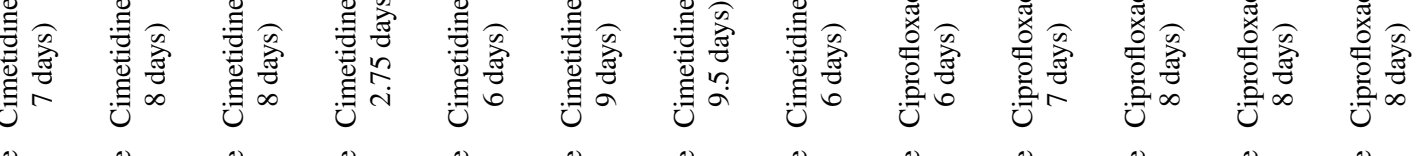

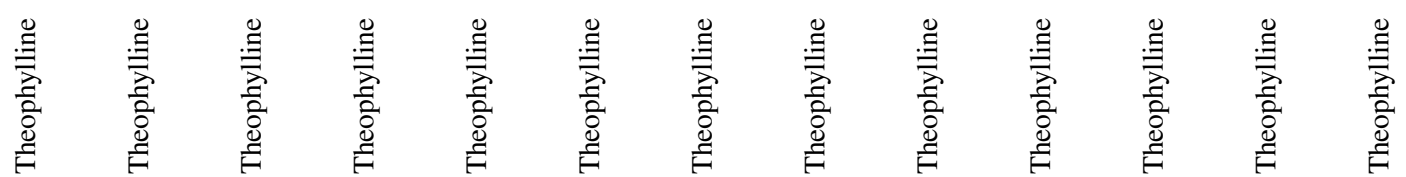




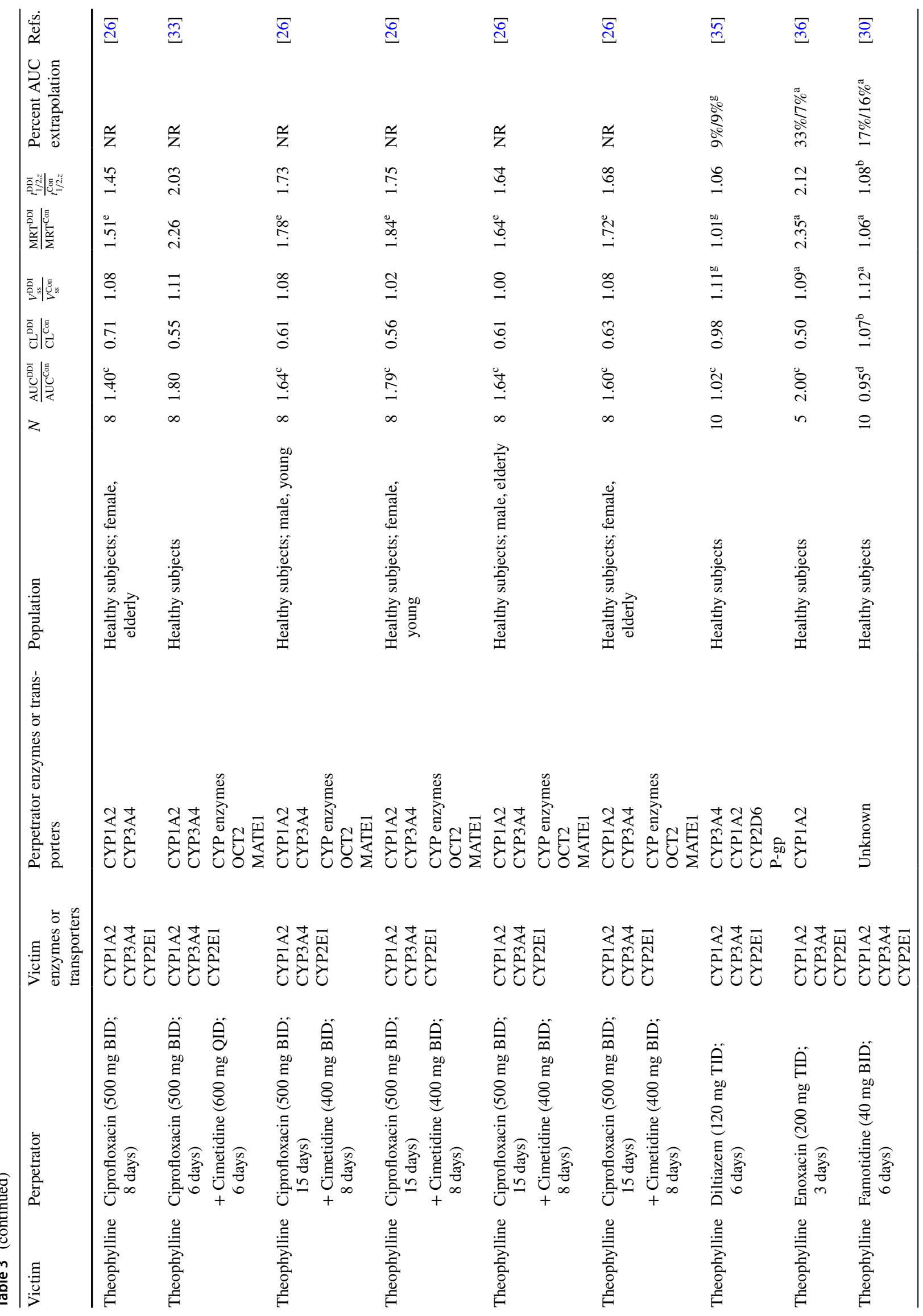




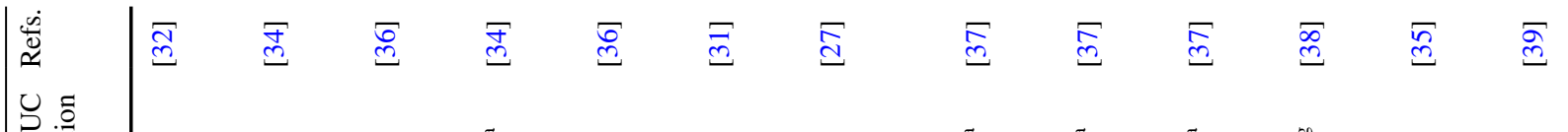
茛迹

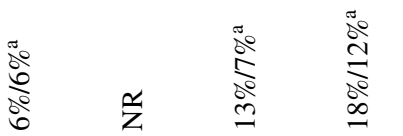
$\frac{8}{8} \stackrel{5}{80}$
$\frac{1}{2} \quad$

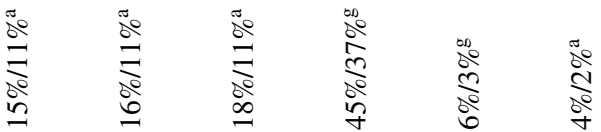

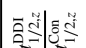

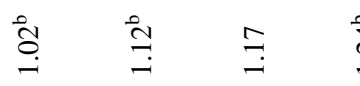
享部若

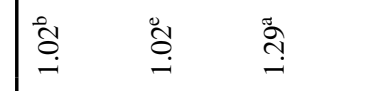

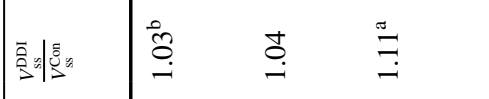

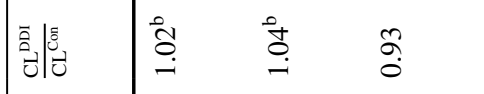
商递
$z$

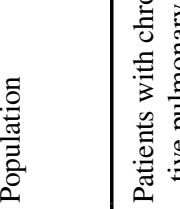
$\begin{array}{ll}\bar{\sigma} & \bar{\sigma} \\ \vdots & \vdots \\ & \infty\end{array}$
$\stackrel{\infty}{i} \stackrel{i}{i}$

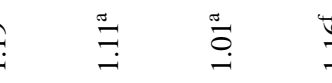

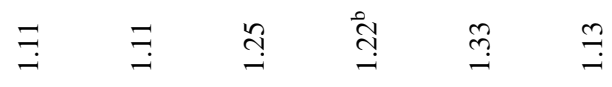

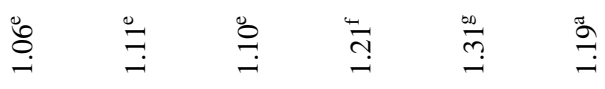

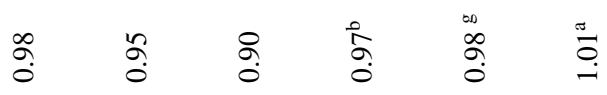
व

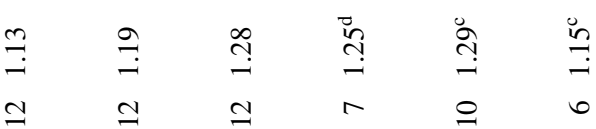

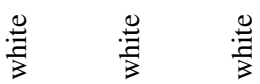

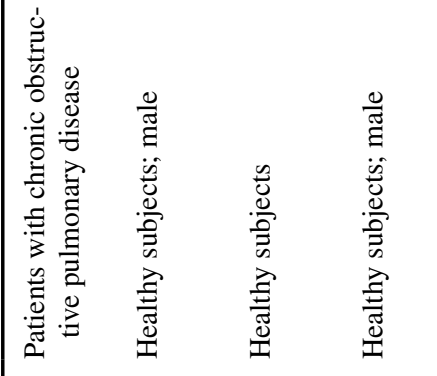

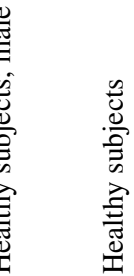

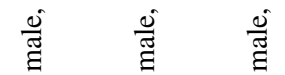

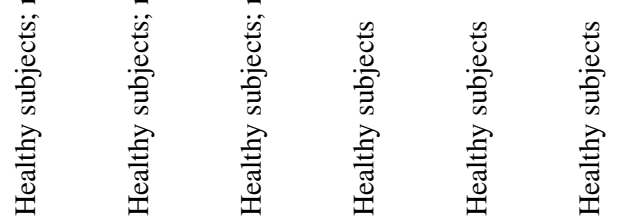

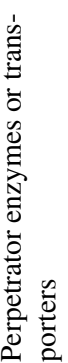

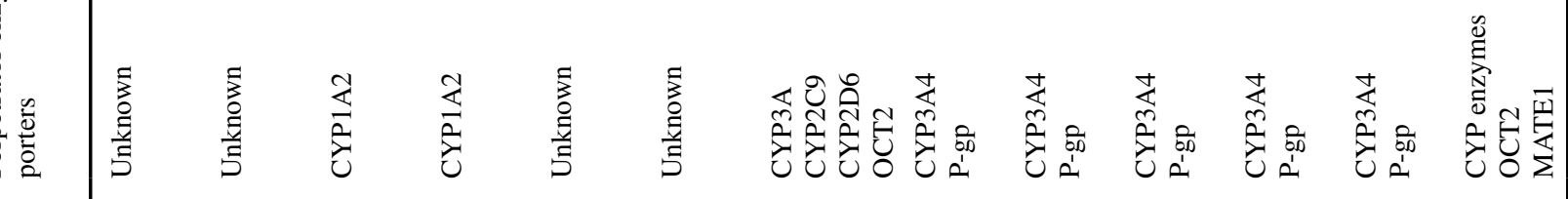

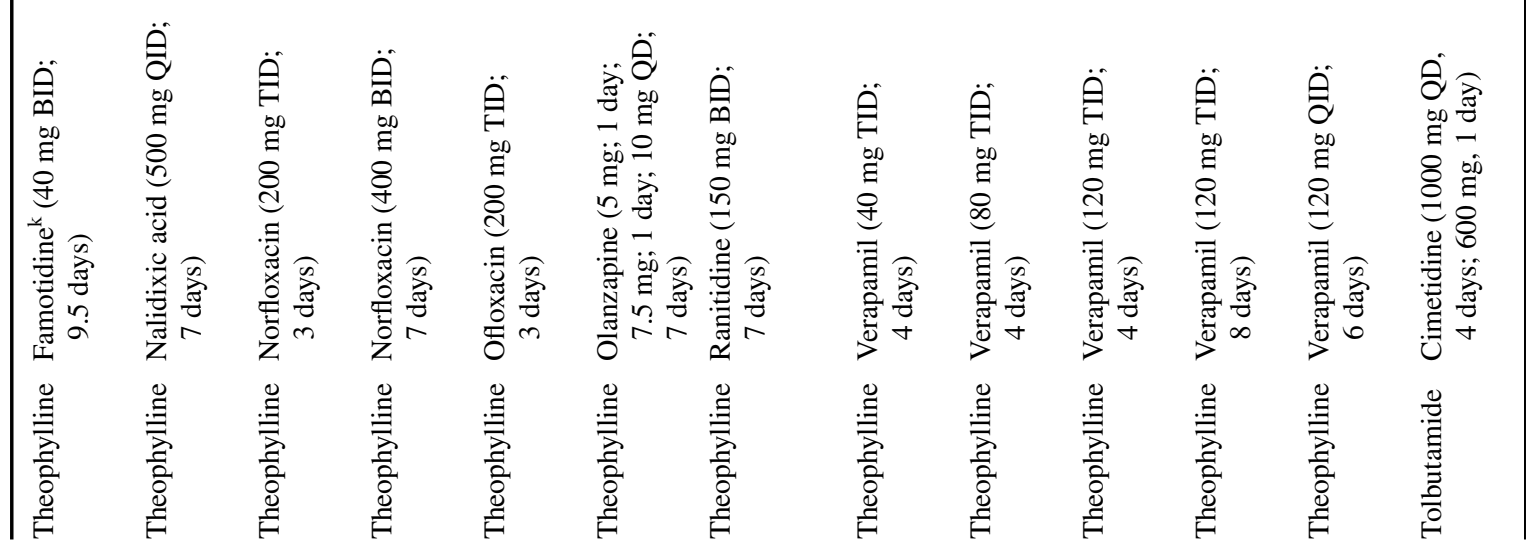




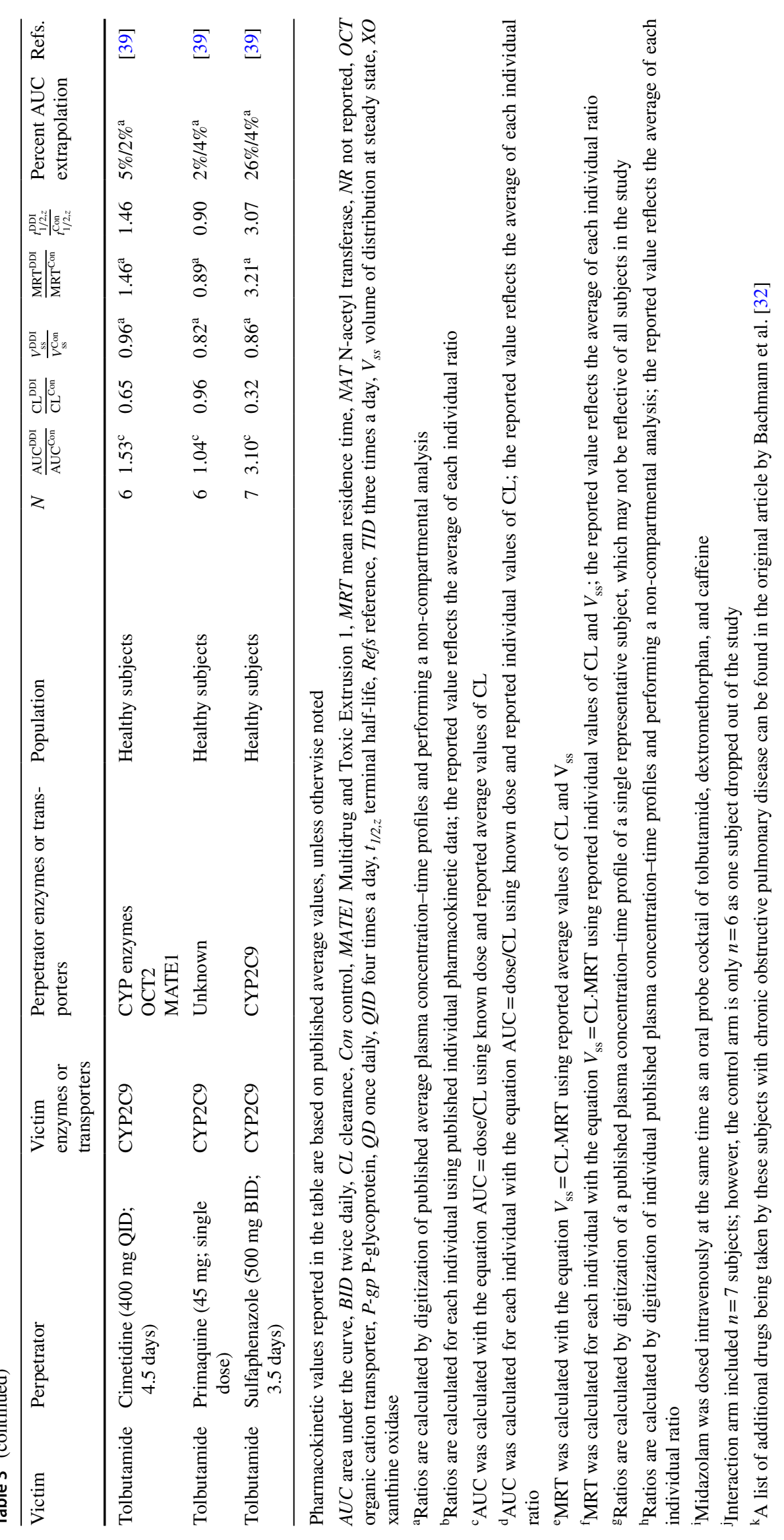




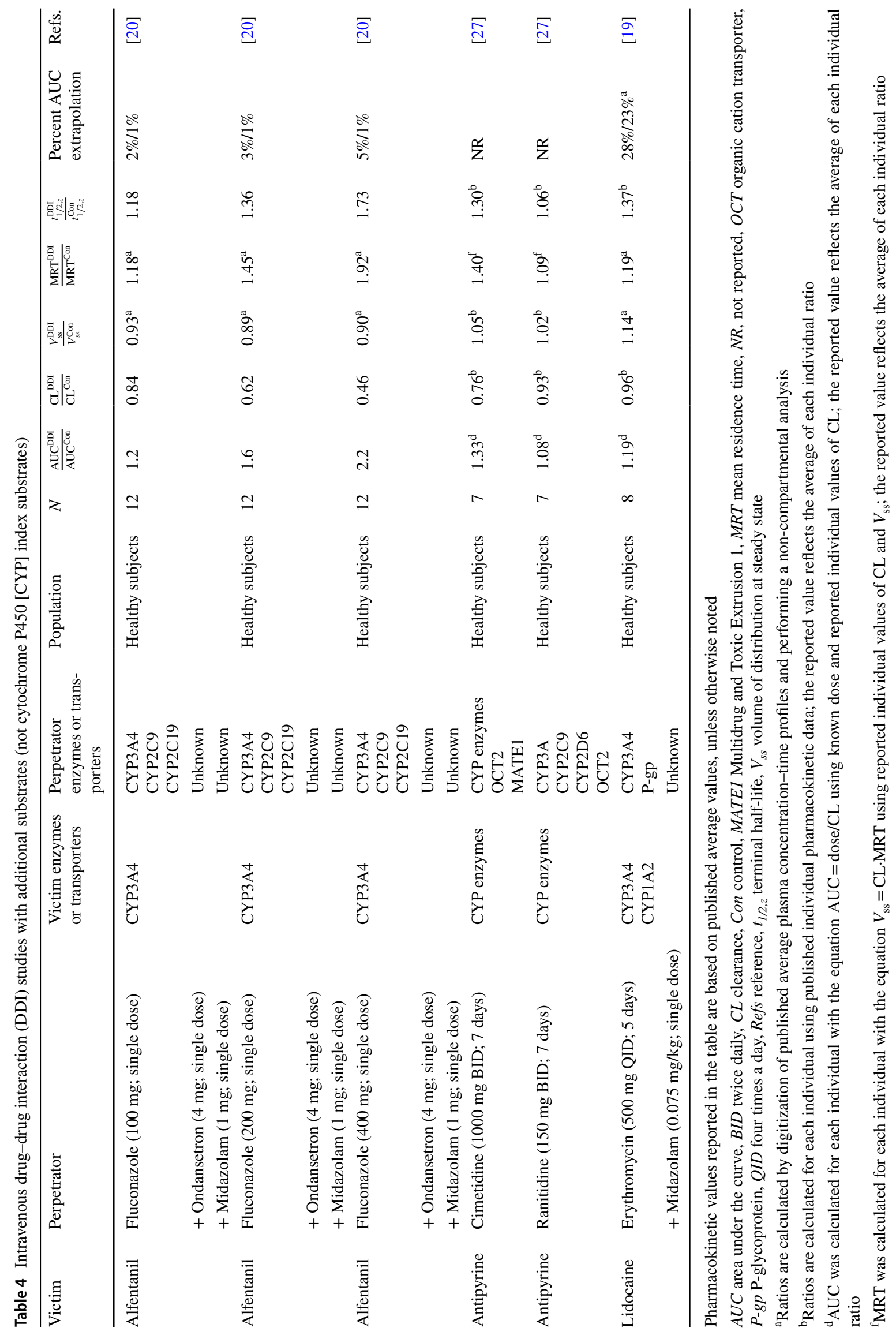




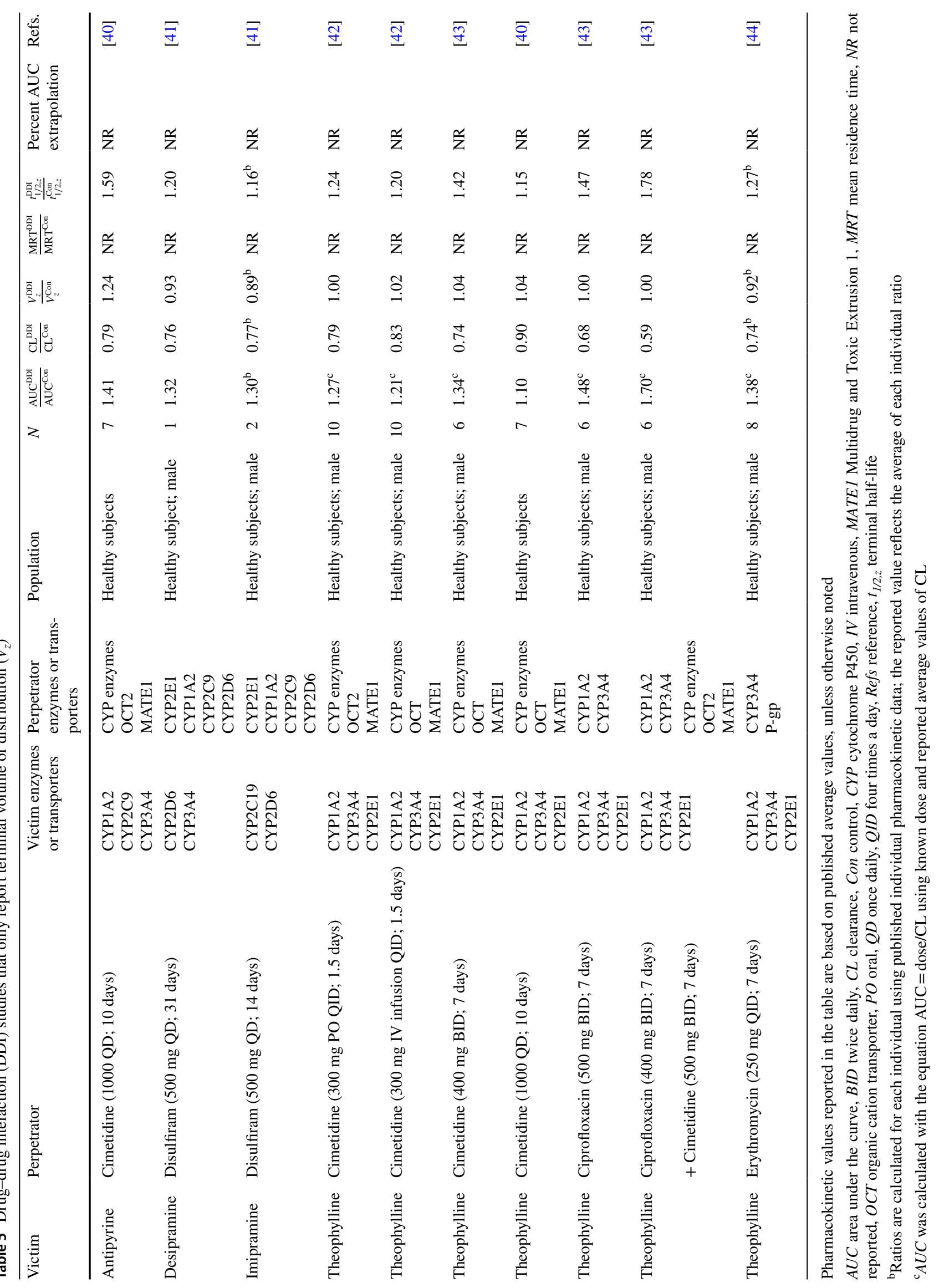


Fig. 1 Box plot depictions of the absolute magnitude of change in victim drug exposure (area under the curve [AUC]) and volume of distribution at steady state $\left(V_{\mathrm{ss}}\right)$ expressed as ratios of interaction to control for a all drug-drug interactions $(n=72)$ and $\mathbf{b}$ the subset of these interactions that are potentially clinically significant (with absolute AUC ratios $>1.3$; $n=49$ ). The box indicates the median and 25th and 75th percentiles, the whiskers range from minimum to maximum values, and each individual data point is also depicted a

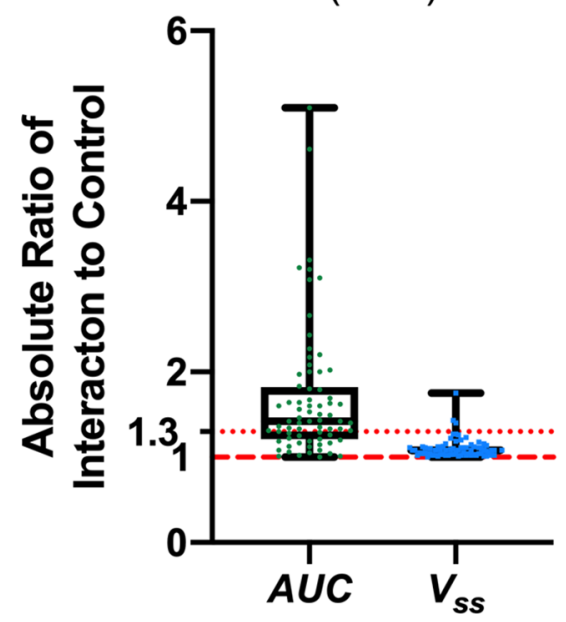

b

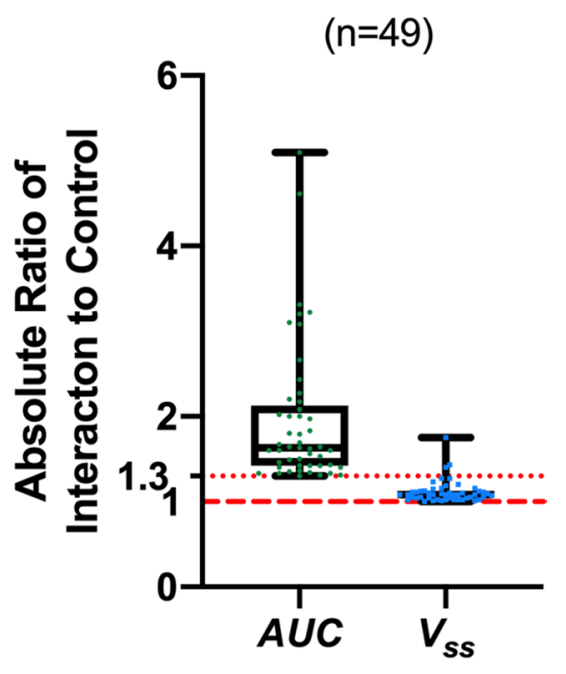

compounded in pharmacogenomic studies where often only a very small number of individuals can be recruited for the less frequently occurring genotypes.

This highlights that for the same drug, $V_{\mathrm{ss}}$ may change significantly between subjects. These findings are in contradiction to the belief that all PK parameters are expected to be similar in homogenous populations, such as in healthy subjects, as the pharmacogenomic interactions studied here included healthy subjects in each arm. As a result, we suggest that it may not appropriate to assume that $V_{\mathrm{ss}}$ is unchanged across different subject populations and therefore, it is crucial to consider clinical study design (parallel vs crossover). Further, based on this observation, we emphasize that the examination of differences in pharmacokinetics in different pharmacogenomic variance or disease-state populations should be considered as a qualitative outcome. Although changes in AUC and CL can reasonably be compared between groups, as $V_{\text {ss }}$ may inherently be different between individuals in each group, changes in terminal half-life should not be considered significant nor be utilized to suggest changes in the dosing regimen between the two populations studied. Further investigation into this finding is warranted, and is an area of high interest to our laboratory.

It should be noted that perpetrator drugs have the potential to displace victim drug from plasma or tissue-binding sites, which may result in $V_{\mathrm{ss}}$ changes. From Eq. (1), changes in protein binding should result in comparable changes for $\mathrm{CL}$ and $V_{\mathrm{ss}}$ with no change in MRT or half-life. However, we find no examples of such an interaction in the same subjects within our dataset. Thus, the data presented here for IV metabolic drug interaction studies very strongly support our contention that $V_{\mathrm{ss}}$ does not change to any significant degree for metabolic DDIs.

The DDI studies evaluated here follow the classic PK trend of changes in CL resulting in an equal but opposite change in MRT, owing to the fact that $V_{\mathrm{ss}}$ remains unchanged for metabolic interactions (Eq. 1) [45]. These relationships are depicted in Fig. 2, where the inverse of ratios of CL changes are plotted against both MRT and $t_{1 / 2, z}$ ratios. The results for each comparison fall very close to the line of unity, highlighting the intuitive trend that decreases in CL result in increases in MRT and $t_{1 / 2, z}$ of approximately equal magnitude. In comparing the AUC-MRT relationship to the AUC $-t_{1 / 2, z}$ relationship, as expected the MRT relationship falls closer to the line of unity than a few of the $t_{1 / 2, z}$ points associated with larger $1 / \mathrm{CL}$ ratios, as $t_{1 / 2, z}$ may change differently than MRT for drugs that display multi-compartment kinetics, and this difference is likely amplified in DDI studies of a larger magnitude. In general, Fig. 2 highlights that changes in CL are opposite in direction but similar in magnitude to MRT and $t_{1 / 2, z}$ and this is in sharp contrast to significant transporter-drug interactions, where decreases in $\mathrm{CL}$ can often be associated with decreases in half-life and MRT, owing to changes in $V_{\mathrm{ss}}$ [2].

As our laboratory has recently presented, knowledge that $V_{\text {ss }}$ remains unchanged in metabolic DDI studies can facilitate the estimation of changes in CL from changes in $F$ following an oral dose [3]. In the Quinney et al. [17] study of the interaction of midazolam and clarithromycin in elderly subjects, the interaction was conducted following both orally and intravenously dosed midazolam. Thus, estimates of changes in CL vs $F$ based on the oral interaction study can be confirmed by examining the observed changes resulting from the IV midazolam interaction study. Following oral dosing, an 8.2-fold increase in midazolam exposure was observed (compared with only a 3.2-fold increase in midazolam AUC in the IV drug interaction study) when clarithromycin was dosed $500 \mathrm{mg}$ twice daily for 7 days (Table 7). Knowing that $V_{\text {ss }}$ largely remains unchanged for IV metabolic DDIs (based on the analysis presented here) 


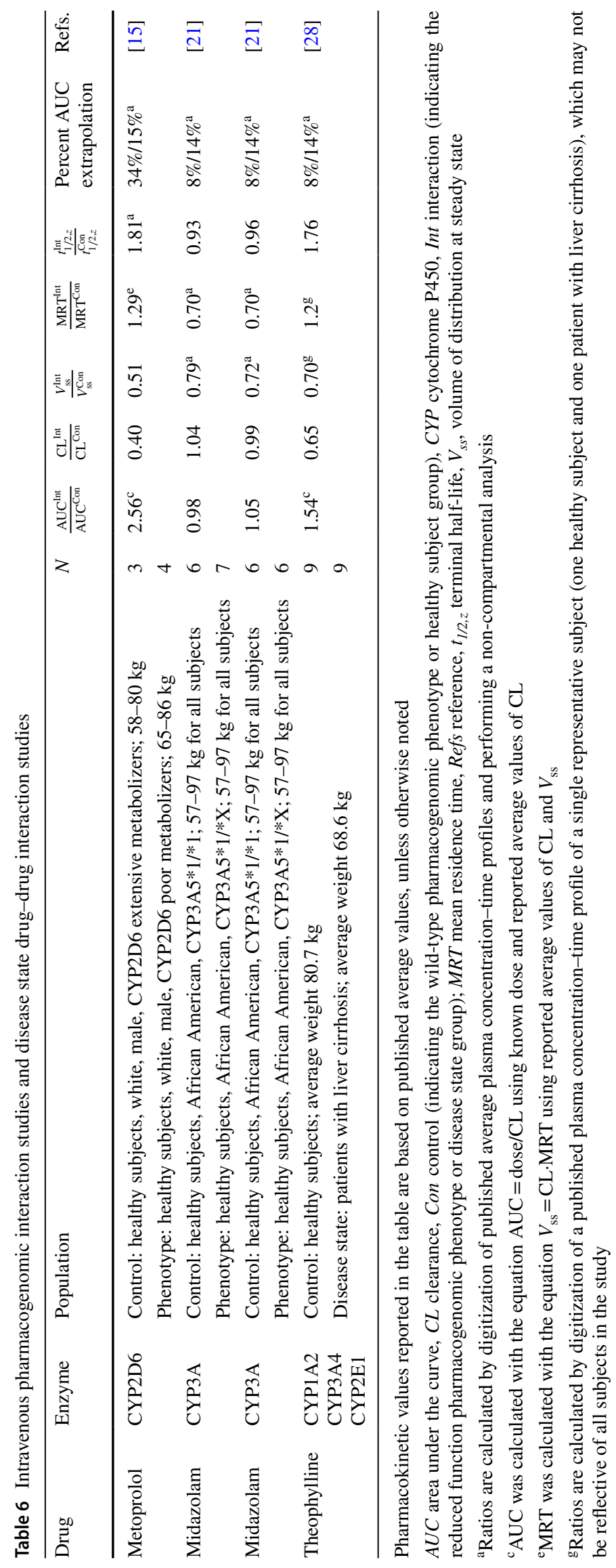


supports the assumption that changes in $V_{\mathrm{ss}} / F$ following an oral dose will reflect changes in $F$ alone. This estimation of $F$ change can subsequently be utilized to assess changes in $\mathrm{CL}$ alone from calculations of apparent CL [3]. Utilizing this methodology, the predicted increase in $F$ was 2.84-fold and CL was predicted to decrease by $60 \%$ (ratio of 0.40 ), compared with the observed 2.12-fold increase in F and 65\% reduction in CL (ratio of 0.35 ) (Table 7). Thus, recognition that $V_{s \mathrm{~s}}$ remains unchanged in metabolic interactions allows the discrimination of two PK parameters thought to be indistinguishable from one another following oral dosing.

\section{Conclusions}

Based on an extensive evaluation of 72 clinical DDI studies, $V_{\text {ss }}$ remains unchanged for IV metabolic drug interactions as expected, with a small minority of outliers (only three) with ratios indicating a change, where for the largest $V_{\mathrm{ss}}$ change, a second study of the same interacting drugs in a different population did not show this marked $V_{\text {ss }}$ change. These results uphold the widely held founding tenant of pharmacokinetics that CL and $V_{\mathrm{ss}}$ are independent parameters. Differences in victim drug $V_{\text {ss }}$ can significantly vary throughout the population due to inter-individual variability that may not necessarily be accounted for by body weight. This highlights that differences in PK parameters observed between groups in pharmacogenomic and disease state studies (or any clinical trial with a parallel study design) should be accompanied with the understanding that $V_{\mathrm{ss}}$ could differ significantly between groups. Therefore, although changes in AUC and CL between groups indicate meaningful differences, terminal half-life differences should be considered qualitative due to their dependence on the inherently variable $V_{\mathrm{ss}}$ value between individuals. Further, following oral dosing the changes in $V_{\mathrm{ss}} / F$ will reflect only changes in $F$ for metabolic interactions. Therefore, this estimation of $F$ change can subsequently be utilized to assess changes in CL
Fig. 2 Ratios of change in $\mathbf{a}$ mean residence time (MRT) and b terminal half-life $\left(t_{1 / 2, z}\right)$ compared with the inverse of change in clearance $(\mathrm{CL})$. The red line indicates the line of unity a

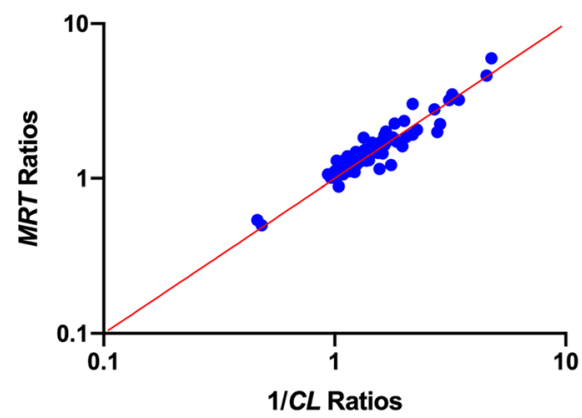

b

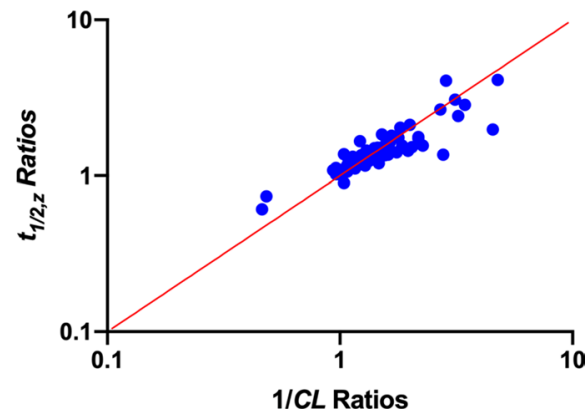

Table 7 Utilization of the Sodhi and Benet methodology [3] to discriminate clearance (CL) from bioavailability $(F)$ changes for orally dosed midazolam (victim) and clarithromycin (perpetrator) from the study of Quinney et al. [17]

\begin{tabular}{|c|c|c|c|c|c|c|c|c|c|}
\hline Victim & Perpetrator & $\frac{\mathrm{AUC}^{\mathrm{DDI}}}{\mathrm{AUC}^{\mathrm{Control}}}$ & $\begin{array}{l}\text { Percent AUC } \\
\text { extrapolation } \\
\text { (DDI/control) }\end{array}$ & $\frac{V_{\mathrm{ss}} / F^{\mathrm{DDI}}}{V_{\mathrm{ss}} / F^{\text {Control }}}$ & $\frac{V_{\mathrm{ss}}^{\mathrm{DDI}}}{V_{\mathrm{ss}}^{\text {Control }}}$ & $\frac{F^{\mathrm{DDI}}}{F^{\text {Control }}}$ & $\frac{\mathrm{CL} / F^{\mathrm{DDI}}}{\mathrm{CL} / F^{\text {Control }}}$ & $\frac{\mathrm{CL}^{\mathrm{DDI}}}{\mathrm{CL}^{\mathrm{Control}}}$ & Refs. \\
\hline $\begin{array}{l}\text { Midazolam } \\
\text { (IV) }\end{array}$ & $\begin{array}{l}\text { Clarithro- } \\
\text { mycin } \\
\text { (500 mg } \\
\text { BID; } \\
7 \text { days) }\end{array}$ & $\begin{array}{l}\text { Observed: } \\
3.2\end{array}$ & $\begin{array}{l}\text { Observed: } \\
44 \% / 19 \%^{\mathrm{a}}\end{array}$ & - & $\begin{array}{l}\text { Observed: } \\
1.16^{\mathrm{a}}\end{array}$ & $\begin{array}{l}\text { Observed: } \\
2.12\end{array}$ & - & $\begin{array}{l}\text { Observed: } \\
0.35\end{array}$ & [17] \\
\hline $\begin{array}{l}{ }^{15} \mathrm{~N}_{3} \text {-Mida- } \\
\text { zolam (oral) }\end{array}$ & $\begin{array}{l}\text { Clarithro- } \\
\text { mycin } \\
\text { (500 mg } \\
\text { BID; } \\
7 \text { days) }\end{array}$ & $\begin{array}{l}\text { Observed: } \\
8.2\end{array}$ & $\begin{array}{l}\text { Observed: } \\
33 \% / 12 \%^{\mathrm{a}}\end{array}$ & $\begin{array}{l}\text { Observed: } \\
0.35^{\text {a }}\end{array}$ & $\begin{array}{l}\text { Assumed: } \\
1\end{array}$ & $\begin{array}{l}\text { Estimated: } \\
2.84^{\mathrm{b}}\end{array}$ & $\begin{array}{l}\text { Observed: } \\
0.14\end{array}$ & $\begin{array}{l}\text { Estimated: } \\
0.40^{\mathrm{b}}\end{array}$ & [17] \\
\hline
\end{tabular}

Pharmacokinetic values reported in the table are based on published average values, unless otherwise noted

$A U C$ area under the curve, BID twice daily, $D D I$ drug-drug interaction, $I V$ intravenous, Refs reference, $V_{s s}$ volume of distribution at steady state ${ }^{a}$ Ratios are calculated by digitization of published average plasma concentration-time profiles and performing a non-compartmental analysis

${ }^{\mathrm{b}}$ Ratios are calculated for each individual using published individual pharmacokinetic data; the reported value reflects the average of each individual ratio 
alone from calculations of apparent CL/F, two parameters that are considered indistinguishable from one another following oral dosing [3].

Acknowledgements These findings were to be presented as a poster at the 2020 American Society for Clinical Pharmacology and Therapeutics (ASCPT) Annual Meeting (18-21 March, 2020, Houston, TX, USA), which was not held because of COVID-19, although the abstract (PII 142) was published in Sodhi et al. (Clin Pharmacol Ther. 2020;107 Suppl.1:S75).

\section{Declarations}

Funding This work was supported in part by a Mary Ann Koda-Kimble Seed Award for Innovation. Jasleen K. Sodhi was supported in part by an American Foundation for Pharmaceutical Education Predoctoral Fellowship, National Institute of General Medical Sciences Grant R25 GM56847, and a Louis Zeh Fellowship. Leslie Z. Benet is a member of the University of California, San Francisco Liver Center supported by a National Institutes of Health Grant P30 DK026743.

Conflict of interest Jasleen K. Sodhi, Caroline H. Huang, and Leslie $\mathrm{Z}$. Benet have no conflicts of interest that are directly relevant to the content of this study.

Ethics Approval Not applicable.

Consent to Participate Not applicable.

\section{References}

1. Grover A, Benet LZ. Effects of drug transporters on volume of distribution. AAPS J. 2009;11:250-61.

2. Benet LZ, Bowman CM, Sodhi JK. How transporters have changed basic pharmacokinetic understanding. AAPS J. 2019;21:103.

3. Sodhi JK, Benet LZ. A simple methodology to differentiate changes in bioavailability from changes in clearance following oral dosing of metabolized drugs. Clin Pharmacol Ther. 2020;108:306-15.

4. Tornio A, Filppula AM, Niemi M, Backman JT. Clinical studies on drug-drug interactions involving metabolism and transport: methodology, pitfalls and interpretation. Clin Pharmacol Ther. 2019;105:1345-61.

5. Isoherranen N, Lutz JD, Chung SP, Hachad H, Levy RH, Ragueneau-Majlessi I. Importance of multi-P450 inhibition in drug-drug interactions: evidence of incidence, inhibition magnitude, and prediction from in vitro data. Chem Res Toxicol. 2012;25:2285-300.

6. Niemi M, Backman JT, Fromm MF, Neuvonen PJ, Kivistö KT. Pharmacokinetic interactions with rifampicin. Clin Pharmacokinet. 2003;42:819-50.

7. Pelkonen O, Mäeenpäeä J, Taavitsainen P, Rautio A, Paunio H. Inhibition and induction of human cytochrome P450 (CYP) enzymes. Xenobiotica. 1998;28:1203-53.

8. Pelkonen O, Turpeinen M, Hakkola J, Honkakoski P, Hukkanen $\mathrm{J}$, Raunio H. Inhibition and induction of human cytochrome P450 enzymes: current status. Arch Toxicol. 2008;82:667-715.

9. Polasek TM, Lin FPY, Miners JO, Doogue MP. Perpetrators of pharmacokinetic drug-drug interactions arising from altered cytochrome P450 activity: a criteria-based assessment. Br J Clin Pharmacol. 2011;71:727-36.
10. Bi Y, Mathialagan S, Tylaska L, Fu M, Keefer J, Vildede A, et al. Organic anion transporter 2 mediates hepatic uptake of tolbutamide, a CYP2C9 probe drug. J Pharmacol Exp Ther. 2018;364:390-8.

11. Kajosaari LI, Laitila J, Neuvonen PJ, Backman JT. Metabolism of repaglinide by CYP2C8 and CYP3A4 in vitro: effect of fibrates and rifampicin. Basic Clin Pharmacol Toxicol. 2005;97:249-56.

12. Wu C-Y, Benet LZ. Predicting drug disposition via application of BCS: transport/absorption/elimination interplay and development of a biopharmaceutics drug disposition classification system. Pharm Res. 2005;22:11-23.

13. Benet LZ, Galeazzi RL. Noncompartmental determination of the volume of distribution steady state. J Pharm Sci. 1979;68:1071-4.

14. Wahlländer A, Paumgartner G. Effect of ketoconazole and terbinafine on the pharmacokinetics of caffeine in healthy volunteers. Eur J Clin Pharmacol. 1989;37:279-83.

15. Leemann TD, Devi KP, Dayer P. Similar effect of oxidation deficiency (debrisoquine polymorphism) and quinidine on the apparent volume of distribution of ( \pm )-metoprolol. Eur J Clin Pharmacol. 1993;45:65-71.

16. Gorski JC, Jones DR, Haehner-Daniels BD, Hamman MA, O'Mara EM, Hall SD. The contribution of intestinal and hepatic CYP3A4 to the interaction between midazolam and clarithromycin. Clin Pharmacol Ther. 1998;64:133-43.

17. Quinney SK, Haehner BD, Rhoades MB, Lin Z, Gorski JC, Hall $\mathrm{SD}$. Interaction between midazolam and clarithromycin in the elderly. Br J Clin Pharmacol. 2008;65:98-109.

18. Olkkola KT, Aranko K, Luurila H, Hiller A, Saarnivarra L, Himberg JJ, Neuvonen PJ. A potentially hazardous interaction between erythromycin and midazolam. Clin Pharmacol Ther. 1993;53:298-305.

19. Swart EL, van der Hoven B, Groeneveld ABJ, Touw DJ, Danhof $\mathrm{M}$. Correlation between midazolam and lignocaine pharmacokinetics and MEGX formation in healthy volunteers. Br J Clin Pharmacol. 2002;53:133-9.

20. Kharasch ED, Walker A, Hoffer C, Sheffels P. Sensitivity of intravenous and oral alfentanil and pupillary miosis as minimally invasive and noninvasive probes for hepatic and first-pass CYP3A activity. J Clin Pharmacol. 2005;45:1187-97.

21. Isoherranen N, Ludington SR, Givens RC, Lamba JK, Pusek SN, Dees EC, et al. The influence of CYP3A5 expression on the extent of hepatic CYP3A inhibition is substrate-dependent: an in vitro-in vivo evaluation. Drug Metab Dispos. 2008;36:146-54.

22. Olkkola KT, Ahonen J, Neuvonen PJ. The effect of systemic antimycotics, itraconazole and fluconazole, on the pharmacokinetics and pharmacodynamics of intravenous and oral midazolam. Anesth Analg. 1996;82:511-6.

23. Tsunoda SM, Velez RL, von Moltke LL, Greenblatt DJ. Differentiation of intestinal and hepatic cytochrome P450 3A activity with use of midazolam as an in vivo probe: effect of ketoconazole. Clin Pharmacol Ther. 1999;66:461-71.

24. Shin K-H, Ahn LY, Choi MH, Moon J-Y, Lee J, Jang I-J, et al. Urinary $6 \beta$-hydroxycortisol/cortisol ratio most highly correlates with midazolam clearance under hepatic CYP3A inhibition and induction in females: a pharmacometabolomics approach. AAPS J. 2016;18:1254-61.

25. Kirby BJ, Collier AC, Kharasch ED, Whittington D, Thummel KE, Unadkat JD. Complex drug interactions of HIV protease inhibitors 1: inactivation, induction, and inhibition of cytochrome P450 3A by ritonavir or nelfinavir. Drug Metab Dispos. 2011;38:1070-8.

26. Loi C-M, Parker BM, Cusak BJ, Vestal RE. Aging and drug interactions. III. Individual and combined effects of cimetidine and ciprofloxacin on theophylline metabolism in healthy male and female nonsmokers. J Pharmacol Exp Ther. 1997;280:627-37. 
27. Breen KJ, Bury R, Desmond MB, Mashford MB, Morphett B, Westwood B, et al. Effects of cimetidine and ranitidine on hepatic drug metabolism. Clin Pharmacol Ther. 1982;31:297-300.

28. Gugler R, Wolf M, Hansen H-H, Jensen JC. The inhibition of drug metabolism by cimetidine in patients with liver cirrhosis. Klin Wochenschr. 1984;62:1126-31.

29. Jackson JE, Powell JR, Wandell M, Bentley J, Dorr R. Cimetidine decreases theophylline clearance. Am Rev Respir Dis. 1981;123:615-7.

30. Lin JH, Chremos AN, Chiou R, Yeh KC, Williams R. Comparative effect of famotidine and cimetidine on the pharmacokinetics of theophylline in normal volunteers. Br J Clin Pharmacol. 1987;24:669-72.

31. Macias WL, Bergstrom RF, Cerimele BJ, Kassahun K, Tatum DE, Callagan JT. Lack of effect of olanzapine on the pharmacokinetics of a single aminophylline dose in healthy men. Pharmacotherapy. 1998;18:1237-48.

32. Bachmann K, Sullivan TJ, Reese JH, Jauregui L, Miller K, Scott $\mathrm{M}$, et al. Controlled study of the putative interaction between famotidine and theophylline in patients with chronic obstructive pulmonary disease. J Clin Pharmacol. 1995;35:529-35.

33. Davis RL, Quenzer RW, Kelly HW, Powell JR. Effect of the addition of ciprofloxacin on theophylline pharmacokinetics in subjects inhibited by cimetidine. Ann Pharmacother. 1992;26:11-3.

34. Prince RA, Casabar E, Adair CG, Wexler DB, Lettieri J, Kasik JE. Effect of quinolone antimicrobials on theophylline pharmacokinetics. J Clin Pharmacol. 1989;29:650-4.

35. Abernethy DR, Egan JM, Dickinson TH, Carrum G. Substrateselective inhibition by verapamil and diltiazem: differential disposition of antipyrine and theophylline in humans. J Pharmacol Exp Ther. 1988;224:994-9.

36. Sano M, Kawakatsu K, Ohkita C, Yamamoto I, Takeyama M, Yamashina H, Goto M. Effects of enoxacin, ofloxacin and norfloxacin on theophylline disposition in humans. Eur J Clin Pharmacol. 1988;35:161-5.

37. Stringer KA, Mallet J, Clarke M, Lindenfeld JA. The effect of three different oral doses of verapamil on the disposition of theophylline. Eur J Clin Pharmacol. 1992;43:35-8.

38. Nielsen-Kudsk JE, Buhl JS, Johannessen AC. Verapamil-induced inhibition of theophylline elimination in healthy humans. Pharmacol Toxicol. 1990;66:101-3.

39. Back DJ, Tjia J, Mönig H, Ohnhaus EE, Park BK. Selective inhibition of drug oxidation after simultaneous administration of two probe drugs, antipyrine and tolbutamide. Eur J Clin Pharmacol. 1988;34:157-63.

40. Roberts RK, Grice J, Wood L, Petroff V, McGuffie C. Cimetidine impairs the elimination of theophylline and antipyrine. Gastroenterology. 1981;81:19-21.

41. Ciraulo DA, Barnhill J, Boxenbaum H. Pharmacokinetic interaction of disulfiram and antidepressants. Am J Psychiatry. 1985;142:1373-4.

42. Cremer KF, Secor J, Speeg KV Jr. The effect of route of administration on the cimetidine-theophylline drug interaction. J Clin Pharmacol. 1989;29:451-6.

43. Loi C-M, Parker BM, Cusack BJ, Vestal RE. Individual and combined effects of cimetidine and ciprofloxacin on theophylline metabolism in male nonsmokers. Br J Clin Pharmacol. 1993;36:195-200.

44. Prince RA, Wing DS, Weinberger MM, Hendeles LS, Riegelman S. Effects of erythromycin on theophylline kinetics. J Allergy Clin Immunol. 1981;68:427-31.

45. Benet LZ, Bowman CM, Koleske ML, Rinaldi CL, Sodhi JK. Understanding drug-drug interaction and pharmacogenomic changes in pharmacokinetics for metabolized drugs. J Pharmacokinet Pharmacodyn. 2019;42:155-63. 